\title{
Successful pembrolizumab treatment of microsatellite instability-high intrahepatic cholangiocarcinoma: A case report
}

YUKI IKEDA ${ }^{1}$, Michihiro Ono ${ }^{1}$, Ginji Omori ${ }^{1}$, Saki Ameda ${ }^{1}$, Michiko Yamada ${ }^{1}$, Tomoyuki Abe $^{1}$, Shigeyuki Fujii ${ }^{1}$, Miri Fujita ${ }^{1}$, and Masahiro Maeda ${ }^{1}$

${ }^{1}$ Shinnittetsu Muroran Sogo Byoin

January 29, 2021

\begin{abstract}
Pembrolizumab is considered to be an effective therapy for patients with microsatellite instability (MSI)-high cancer. Here, we report a case of MSI-high cholangiocarcinoma effectively treated with pembrolizumab. MSI status should be actively evaluated in patients with cholangiocarcinoma.
\end{abstract}

\section{Hosted file}

main document ver.2.pdf available at https://authorea.com/users/392592/articles/506396successful-pembrolizumab-treatment-of-microsatellite-instability-high-intrahepaticcholangiocarcinoma-a-case-report

\section{Hosted file}

Figure ver.1.pptx available at https://authorea.com/users/392592/articles/506396successful-pembrolizumab-treatment-of-microsatellite-instability-high-intrahepaticcholangiocarcinoma-a-case-report 